Article

\title{
Electrosprayed Nanoparticles Based on Hyaluronic Acid: Preparation and Characterization
}

\author{
Petr Snetkov*(D), Kseniia Zakharova ${ }^{\mathbb{D}}$, Svetlana Morozkina, Mikhail Baranov, \\ Roman Olekhnovich $\mathbb{D}$ and Mayya Uspenskaya \\ Institute BioEngineering, ITMO University, Kronverkskiy prospekt, 49A, 197101 St. Petersburg, Russia; \\ zakharova_kseniia@lenta.ru (K.Z.); Morozkina.Svetlana@gmail.com (S.M.); mbaranov@mail.ru (M.B.); \\ r.o.olekhnovich@mail.ru (R.O.); mv_uspenskaya@mail.ru (M.U.) \\ * Correspondence: ppsnetkov@itmo.ru; Tel.: +7-812-232-37-74
}

Received: 17 October 2020; Accepted: 24 November 2020; Published: 27 November 2020

\begin{abstract}
Modern drug delivery systems demand the development of targeted polymer-carriers with the set of obligatory requirements. Thus, such capsules must have total biocompatibility, biodegradability, and possess non-allergenic, and non-tumorigenic properties. Hyaluronic acid (HA), as a natural linear polysaccharide that is included in the pericellular and extracellular matrixes, satisfies all these demands in the best possible way. In this study, the biopolymer nanoparticles with an average diameter of $300 \mathrm{~nm}$ were successfully obtained from aqueous HA solutions by electrospraying technique and characterized. Due to the presence of active functional groups in the structure of HA, such polymer particles can incorporate various pharmaceutical agents. This finding expands the investigation and subsequent application of drug-loaded nanoparticles based on HA as challenging and advanced targeted delivery systems.
\end{abstract}

Keywords: biopolymer; drug delivery; electrical conductivity; electrospinning; electrospraying; hyaluronic acid; nanoparticles; spraying solutions; surface tension; viscosity

\section{Introduction}

Hyaluronic acid (HA) is a linear glycosaminoglycan that consists of regularly alternating residues of D-glucuronic acid and N-acetyl-D-glucosamine with a molecular weight of 5-20,000 kDa [1]. It can be found in various tissues and fluids, and in the greatest quantities, it is present in skin, articular cartilage, and synovial fluid [2]. Hyaluronic acid has various functions ubiquitous in the body. Its ability to trap water allows hyaluronic acid to act as a barrier to control changes in water content. HA acts as a space-filler and considering the rheological properties it also performs as a joint lubricator $[3,4]$. Hyaluronic acid performs not only structural functions but also plays an important role in the processes of inflammation, tissue regeneration, and immunosuppression [5]. Due to its unique biological and physicochemical properties, HA is actively investigated as a promising biomaterial for various medical, pharmaceutical, food, and cosmetic applications. One of the important areas of application of HA is its use as a drug carrier in individualized targeted drug and vaccines [6] delivery systems and drug screening systems for personalized medicine [7]. Interestingly that apart from drugs the transplanted cells could be encapsulated by HA-hydrogels [6] that increase the topicality of studies in the area of HA and cross-linked HA.

HA binds to various receptors, mediating various biological effects (Figure 1). 


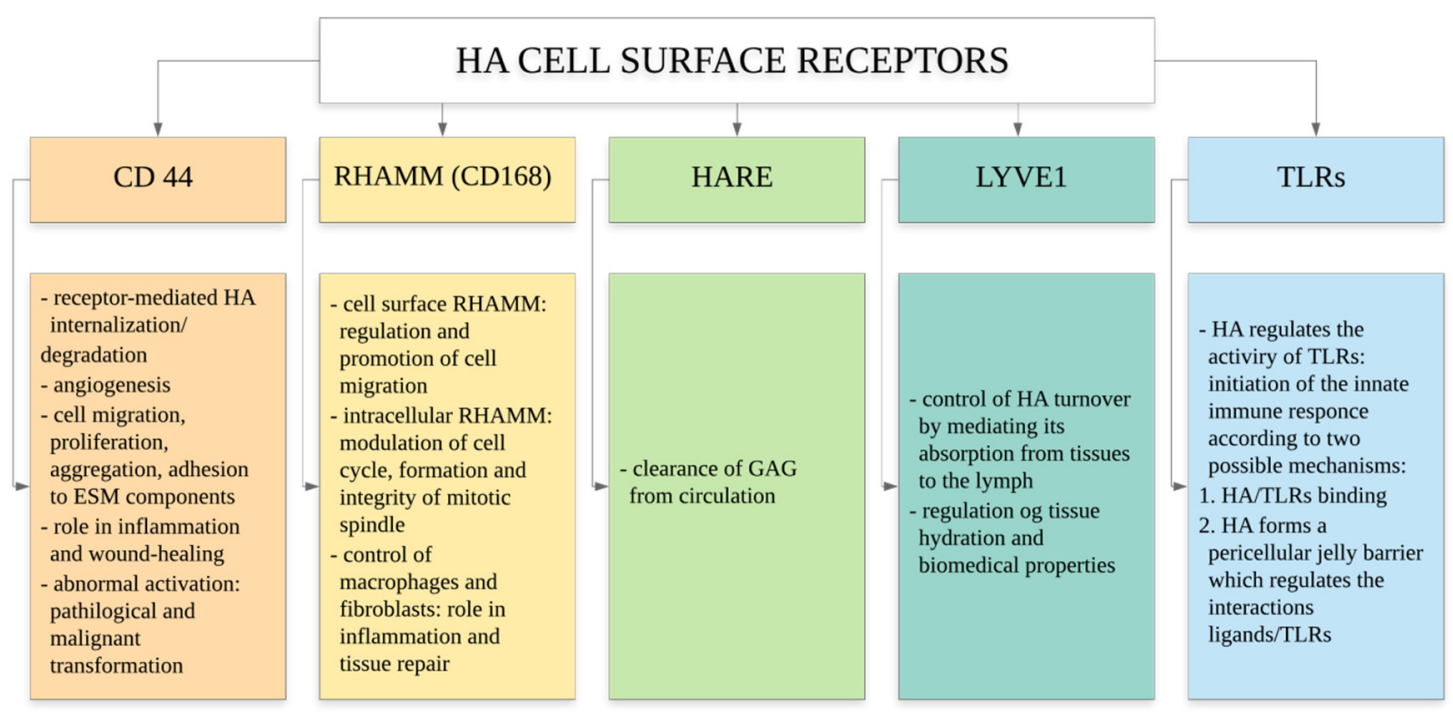

Figure 1. Hyaluronic acid cell surface receptors and their functions [5].

The use of hyaluronic acid as a drug carrier for the treatment of tumors is based on the fact that, by binding to specific receptors, it is involved in the activation of intracellular signaling cascades associated with tumor growth and tumor cell adhesion [8]. It was previously established that an overexpression of CD44 receptor correlates with an enhanced metastasis formation [9]. The mechanism of action of drug-loaded HA was proposed by P. Gibbs et al. [10], and the effectiveness of HA as a drug carrier of irinotecan for the treatment of colorectal cancer was confirmed.

There are many types of drug delivery vehicles, such as liposomes, dendrimers, hydrogels, magnetic nanoparticles, quantum dots, and polymer nanoparticles [11]. Polymer nanoparticles are particles prepared from a natural or synthetic polymer with a size range from 10 to $1000 \mathrm{~nm}$ [12]. Nanosized molecules allow better uptake of the particles by cells (at a size less than $1 \mu \mathrm{m}$ ) and provide the prolonged mode of action in the bloodstream [13] which combined with such characteristics as biodegradability, non-toxicity, the biocompatibility of natural polymers became an effective and safe drug delivery carrier with significantly fewer side effects.

Polymer nanoparticles can be obtained by an efficient and versatile method called electrohydrodynamic jetting, which is driven by adjustable constant high electric voltage. Polymer solution flows out through an injecting capillary nozzle with a predetermined volumetric flow rate. Under the influence of electric forces an initial continuous, stationary, accelerated, and thinning free stream forms, the axis of which coincides with the general direction of the electric field. As a result, the jet is formed in the form of a cone, which is called Taylor Cone [14]. Depending on the parameters of the process and the properties of the solution, the jet can split into many smaller jets, leading to the formation of fibers (electrospinning), or the formation of drops of the polymer solution can occur, which will lead to the formation of particles, the so-called electrospraying process [15]. Thereat, electrosprayed nanoparticles based on polysaccharides such as chitosan, hyaluronic acid, alginic acid, etc., are in demand in modern medicine.

Among the advantages of electrospinning technology, one can single out the simplicity of the hardware execution of the method, ease of materials combination, variety of obtained nanostructures, and ability to scale up to mass production [16]. Recently we published data about the successful obtaining of nanofibers based on hyaluronic acid with integrated natural biologically active compounds curcumin and usnic acid [17]. This fact was the basis for the current work that is aimed to investigate the possibility for the obtaining of nanoparticles containing drug molecules for cancer and other diseases treatment. Keeping in mind this main direction, we have first investigated the possibility for nanoparticles obtaining based on pure native hyaluronic acid from aqueous solutions by electrospraying technique. Results are demonstrated in this paper. Moreover, apart from SEM and statistical analysis the 
physical parameters of polymer solutions have been carefully evaluated. Advanced and biodegradable materials for drug delivery systems have been developed.

\section{Materials and Methods}

\subsection{Materials}

Sodium hyaluronate HA-T with molecular weight equal to 1.29 MDa (glucuronic acid content $45 \%$ ) was purchased from (Bloomage Freda Biopharm CO., LTD. Jinan, China). Biopolymer was used without any purification. Distilled water was used as a solvent.

\subsection{Electrospraying Polymer Solutions and Evaluation of Their Properties}

Hyaluronic acid sodium salt was dissolved in distilled water to obtain solutions with a concentration from 2.5 to $15.0 \mathrm{mg} / \mathrm{mL}$ at a pitch of $2.5 \mathrm{mg} / \mathrm{mL}$. Solutions were stirred on the magnetic mixer at $50{ }^{\circ} \mathrm{C}$ for $24 \mathrm{~h}$. Obtained solutions were kept for $60 \mathrm{~min}$ at room conditions for the stabilization and deaeration process.

Mettler Toledo Densito 30PX (USA) density meter was used for density analysis of hyaluronic acid solutions. Surface tension was determined by drop shape analyzer KRUSS DSA 100 (KRUSS, Hamburg, Germany). Electrical conductivity was measured by InoLab Cond 720 (Houston, Texas, USA) with four-electrode-conductivity cell TetraCon 325. Rheological properties were determined by Anton Paar Physica MCR-502 rheometer (Anton Paar, Graz, Austria) with cylindrical measuring system CC27/T200/SS.

\subsection{Electrospraying Technique}

Nanoparticles were obtained using the electrospinning system NANON-01A (MECC CO., LTD., Tokyo, Japan). The basic scheme of the electrospraying process (as a particular case of electrohydrodynamic jetting) is shown in Figure 2 and was described in detail previously [18].

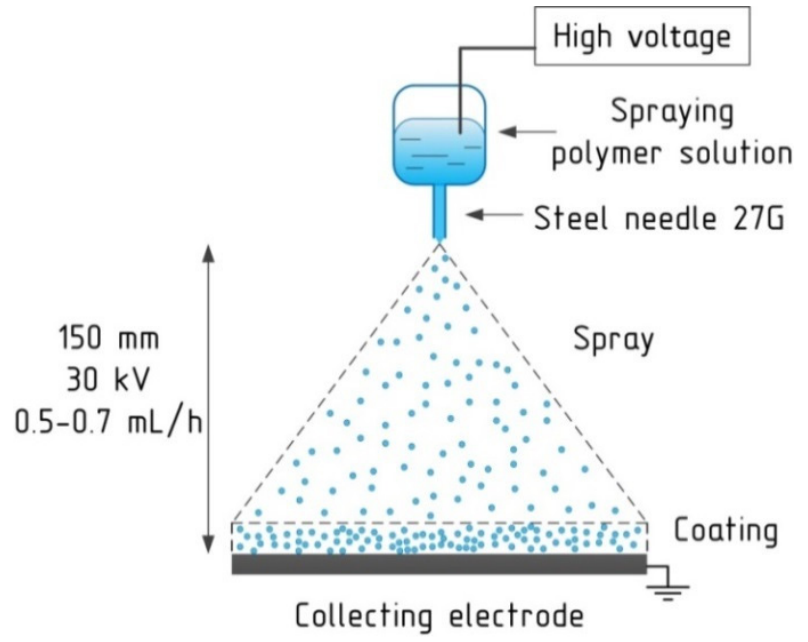

Figure 2. Principal scheme of the electrospraying process and technological parameters.

Electrospraying was carried out at room temperature $\left(23.0 \pm 2{ }^{\circ} \mathrm{C}\right)$ and a relative humidity equal to $30 \%$. Process conditions were set as follows: electric potential $30 \mathrm{kV}$; feed velocity $0.5-0.7 \mathrm{~mL} / \mathrm{h}$; traverse rate $10 \mathrm{~mm} / \mathrm{s}$, stainless steel needles $27 \mathrm{G}$; plate steel collecting electrode $150 \times 200 \mathrm{~mm}(\mathrm{~L} \times \mathrm{B})$; distance between collecting electrode and needle equal to $150 \mathrm{~mm}$. Electrospraying process was carried out at the silicone plates $10 \times 10 \times 0.25 \mathrm{~mm}(\mathrm{~L} \times \mathrm{B} \times \mathrm{H})$ for $10 \mathrm{~min}$ with subsequent dehumidification in the NANON chamber for $5 \mathrm{~min}$. 


\subsection{Morphology and Diameters of Nanoparticles. Statistical Analysis}

The scanning electronic microscope (SEM) MERLIN Carl Zeiss was used for morphology analysis and diameters measurement. The accelerating voltage (EHT) of $1 \mathrm{kV}, 2 \mathrm{kV}$, and $5 \mathrm{kV}$ were applied to gain better image contrast, signal $\mathrm{A}=$ InLens or SE2, and the working distance was from 2.5 to $4.6 \mathrm{~mm}$. The samples were measured without conductive coating.

ImageJ (National Institutes of Health, New York, NY, USA) was used for fiber diameter measurement [19].

Statistical analysis of the obtained nanoparticles was done by OriginPro 2019b (OriginLab Corporation, Northampton, MA, USA). Several images were used for diameter distribution analysis.

\section{Results and Discussion}

\subsection{Properties of Polymer Solutions}

It is known that the specific conditions and maintenance of the main parameters of polymer solutions at certain levels (ranges) are necessary to provide electrohydrodynamic jetting. Such parameters include rheological characteristics (dynamic viscosity), density, electrical conductivity, and surface tension. For instance, low solution viscosity may cause destabilizing action on the polymer jet. By contrast, solutions with high viscosity are liable to obstruct the feeding tube of equipment utilized [15]. At the same time, the high value of surface tension, low electrical resistance, and low potential rate of solvent evaporation common to hyaluronic acid aqueous solutions could hinder its electrospinning and electrospraying. For this reason, it is necessary to evaluate the key parameters of polymer solutions. The main measured parameters are summarized in Table 1.

Table 1. Key parameters of the electrospraying polymer solutions.

\begin{tabular}{cccc}
\hline $\begin{array}{c}\text { HA Concentration } \\
\mathbf{m g} / \mathbf{m L}\end{array}$ & $\begin{array}{c}\text { Electrical Conductivity } \\
\boldsymbol{\mu S} / \mathbf{c m}\end{array}$ & $\begin{array}{c}\text { Density } \\
\mathbf{g} / \mathbf{c m}^{3}\end{array}$ & $\begin{array}{c}\text { Surface Tension } \\
\mathbf{m N} / \mathbf{m}\end{array}$ \\
\hline 2.5 & $470 \pm 29$ & $0.9987 \pm 0.0003$ & $72.50 \pm 1.05$ \\
\hline 5.0 & $834 \pm 23$ & $0.9998 \pm 0.0003$ & $71.54 \pm 0.45$ \\
\hline 7.5 & $1219 \pm 22$ & $1.0008 \pm 0.0003$ & $71.22 \pm 0.83$ \\
\hline 10.0 & $1603 \pm 38$ & $1.0019 \pm 0.0002$ & $70.84 \pm 0.38$ \\
\hline 12.5 & $1946 \pm 50$ & $1.0025 \pm 0.0002$ & $69.99 \pm 0.89$ \\
\hline 15.0 & $2363 \pm 40$ & $1.0037 \pm 0.0003$ & $68.95 \pm 0.29$ \\
\hline
\end{tabular}

\subsubsection{Electrical Conductivity}

Electrical conductivity is one of the main parameters of the polymer solutions for electrospraying and electrospinning techniques. Hyaluronic acid is a natural polysaccharide with a polyelectrolyte nature. It has been established that the charged polymer solutions could have electrolytic conductivity [20]. Moreover, hyaluronic acid is considered as the electroactive polymer [21]. Thus, aqueous solutions based on HA demonstrate high electrical conductivity levels which can inhibit the electrospraying process [18].

The established in our solutions relationship between the electrical conductivity of the solution and hyaluronic acid concentration at $25.0 \pm 1.0^{\circ} \mathrm{C}$ is demonstrated in Figure 3.

The increasing of hyaluronic acid content increases ion quantity and solution conductivity, consequently. On the one side, the polymer solutions have to possess a definite electrical conductivity level to promote the charge transport from the needle to the solution. On the other side, high electrical conductivity values along with the low evaporative capacity of aqueous hyaluronic acid solutions could lead to the voltage breakdown between the spinneret and collecting electrode. Thereby, electrical 
conductivity is considered as a unique required parameter for electrospinning and electrospraying techniques and biomaterials obtained by these methods.

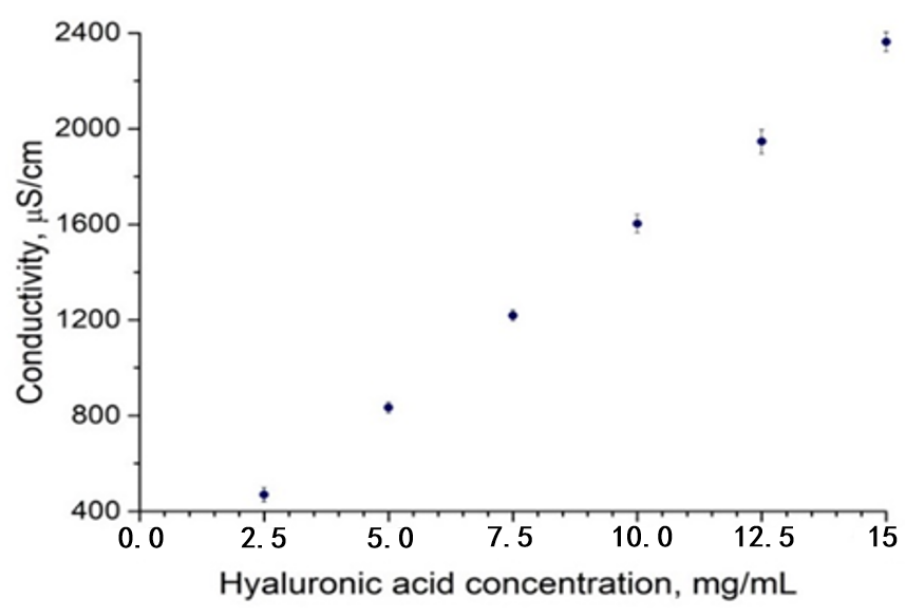

Figure 3. Electrical conductivity as a function of hyaluronic acid concentration at $25.0 \pm 1.0^{\circ} \mathrm{C}$.

\subsubsection{Density}

Density is an important parameter for the measurement of surface tension. Figure 4 demonstrates the dependence of density from hyaluronic acid concentration at $25.0 \pm 1.0^{\circ} \mathrm{C}$. Evidently, density increases with polymer concentration increases and dependence has a linear character. Note, that the density of deionized water at $25.0{ }^{\circ} \mathrm{C}$ is equal to $0.9970 \mathrm{~g} / \mathrm{cm}^{3}$ [22]. The results obtained correlate to the previous studies $[23,24]$.

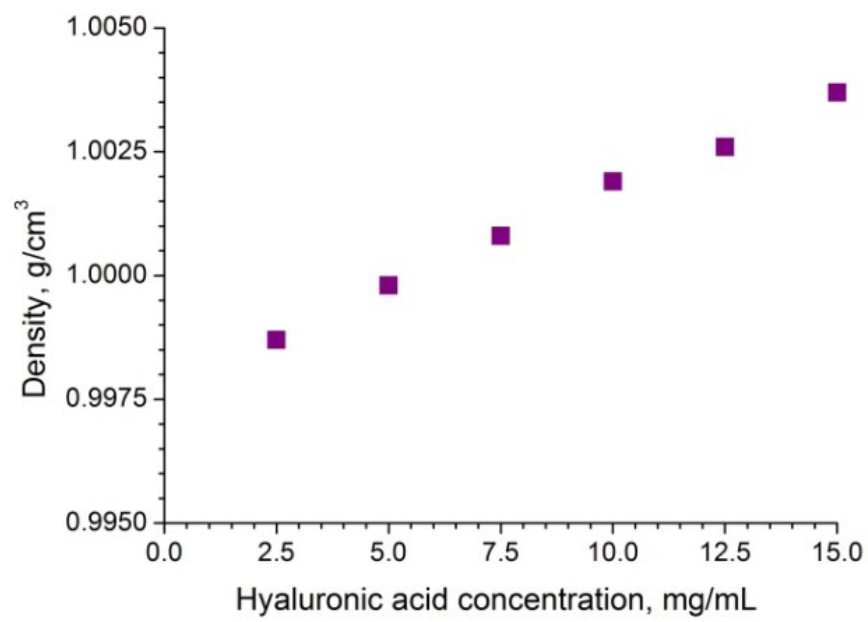

Figure 4. Dependence of the solution density from hyaluronic acid concentration at $25.0 \pm 1.0{ }^{\circ} \mathrm{C}$.

\subsubsection{Surface Tension}

Surface tension has an important role in electrohydrodynamic jetting. Initially, after supplementation of the high electric voltage, electrical like charges are prompted on the surface of the drop of the polymer solution. This charge leads to the overcome of the surface tension forces and the alteration of drop shape from spherical to conical. After the excess of the electric field degree over the specified critical value, the electrostatic forces surpass the polymer solution surface tension and the dispersion of polymer solution is started [25].

Figure 5 shows the dependence of the surface tension from hyaluronic acid concentration at $20.0 \pm 1.0^{\circ} \mathrm{C}$. A slight decline in the surface tension is observable with an increase in polymer 
concentration. Note, that the surface tension of distilled water at $20.0^{\circ} \mathrm{C}$ is equal to $72.74 \mathrm{mN} / \mathrm{m}$ [22]. Our results correlate with the data published in the article [26]. Rapid changes in the surface tension are not identified because of the shorting of the concentration in which the entanglement process of polymer chains is started.

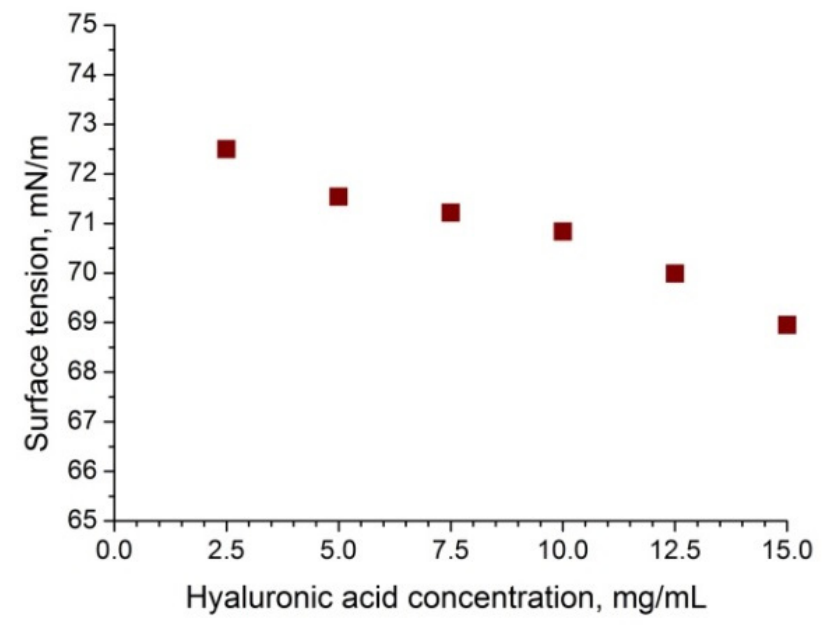

Figure 5. Dependence of the surface tension from hyaluronic acid concentration at $25.0 \pm 1.0^{\circ} \mathrm{C}$.

\subsubsection{Rheological Characteristics}

Dynamic viscosity of electrospraying solution is one of the key technological parameters showing the possibility of its transporting through the feeding system and thin needles (nozzles). Hyaluronic acid is known to organize the tertiary helicoid structure [27-31]. Furthermore, hyaluronic acid polymer chains tend to intertwine each other if the polymer concentration in water solution more than $1.0 \mathrm{wt} . \%[32,33]$ which leads to a rapid viscosity increase. High viscosity level results in hindering or even clotting of the feeding system of equipment utilized.

The viscosity of hyaluronic acid aqueous solutions, regardless of the concentration, directly depends on the shear rate and follows the non-linear law, which is typical for non-Newtonian solutions [34]. As demonstrated in Figure 6, the dynamic viscosity of hyaluronic acid aqueous solutions with a concentration from 2.5 to $15.0 \mathrm{mg} / \mathrm{mL}$ at $25.0 \pm 0.2{ }^{\circ} \mathrm{C}$ is decreasing with the shear rate increase.

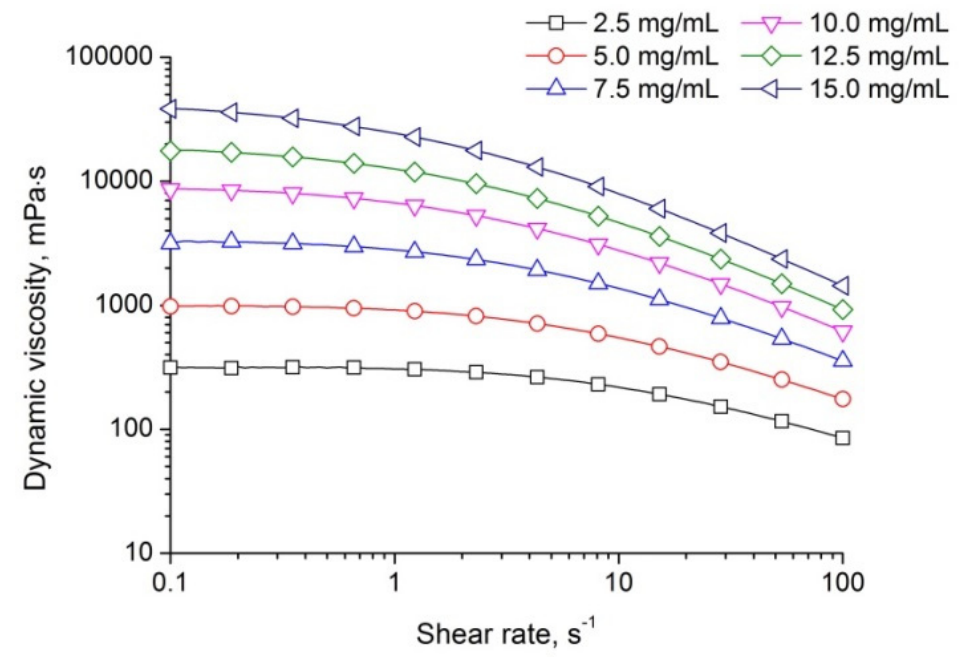

Figure 6. Dynamic viscosity of hyaluronic acid solutions as a function of shear rate and polymer concentration at $25.0 \pm 0.2{ }^{\circ} \mathrm{C}$. 


\subsubsection{Solutions Electrosprayability}

In this study, hyaluronic acid nanoparticles were obtained by electrospraying with a biopolymer concentration in an aqueous solution from 2.5 to $15.0 \mathrm{mg} / \mathrm{mL}$. The electrospraying process could be characterized as stable and non-fluctuating across the entire concentration range except for the last. Interestingly, the electrospraying process had several special aspects. Firstly, a visual contour of the envelope cone was unusually wide. Secondly, a straight segment of a polymer jet was absent: the whipping section begins with the steel needlepoint. Note, that further increase in hyaluronic acid concentration led to an increase of jet splashes, large drops, and a significant deterioration in electrospraying up to its total shutdown.

\subsubsection{SEM Analysis}

SEM photomicrographs of the nanoparticles obtained from hyaluronic acid solutions having various concentrations under $30 \mathrm{kV}$ are demonstrated in Figures 7-12. SEM images were taken at several magnifications.

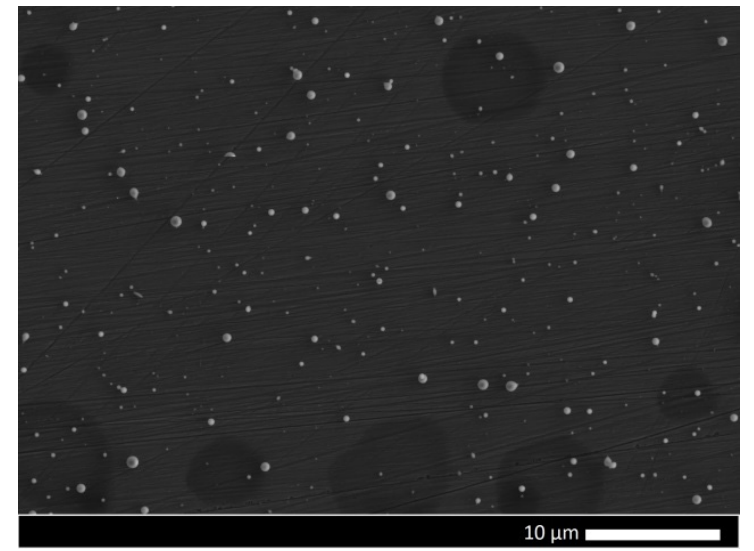

(a)

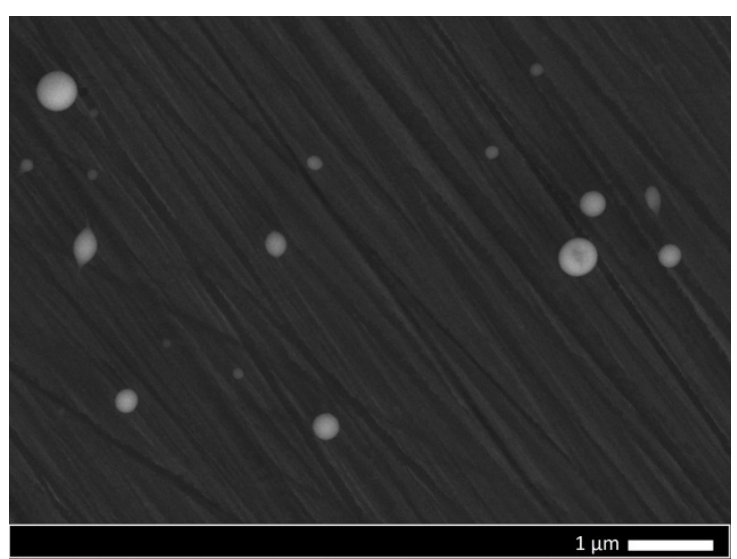

(b)

Figure 7. SEM photomicrographs of nanoparticles electrosprayed from the hyaluronic acid solutions with concentration $2.5 \mathrm{mg} / \mathrm{mL}$ under $30 \mathrm{kV}$ : (a) magnification 4000×; (b) magnification 25,000×.

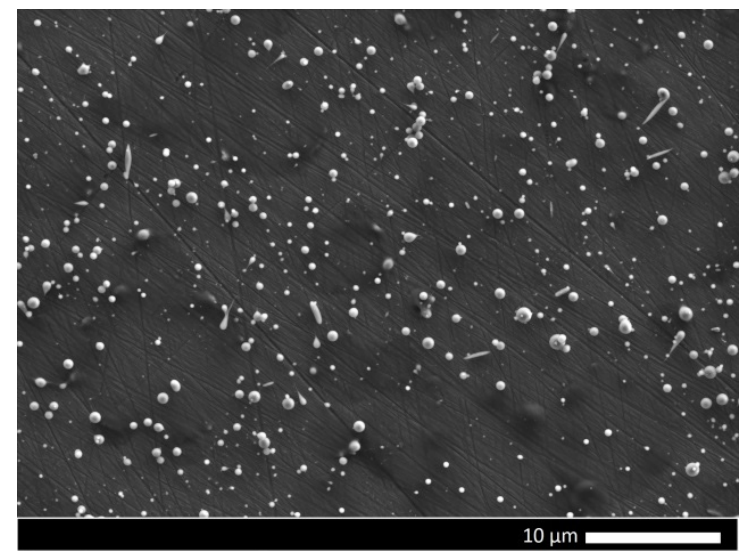

(a)

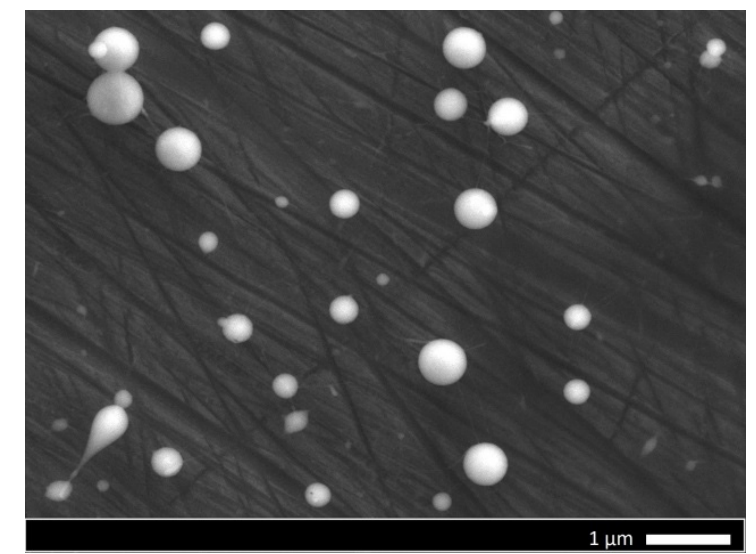

(b)

Figure 8. SEM photomicrographs of nanoparticles electrosprayed from the hyaluronic acid solutions with concentration $5.0 \mathrm{mg} / \mathrm{mL}$ under $30 \mathrm{kV}$ : (a) magnification 4000×; (b) magnification 25,000×. 


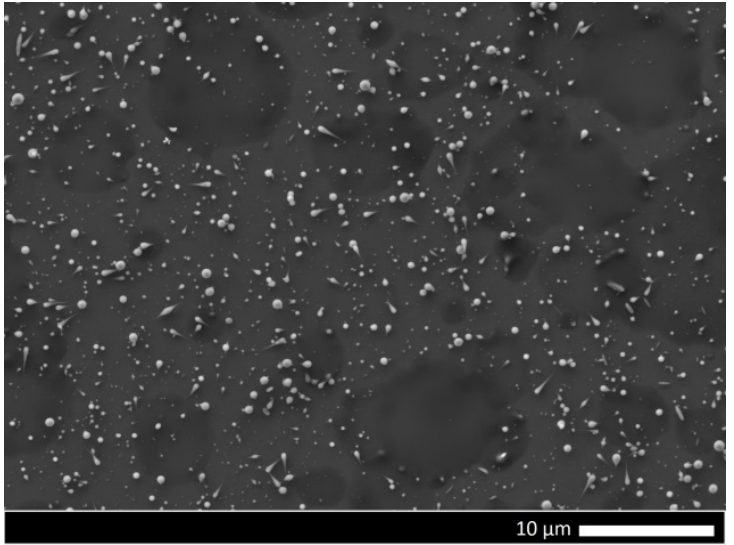

(a)

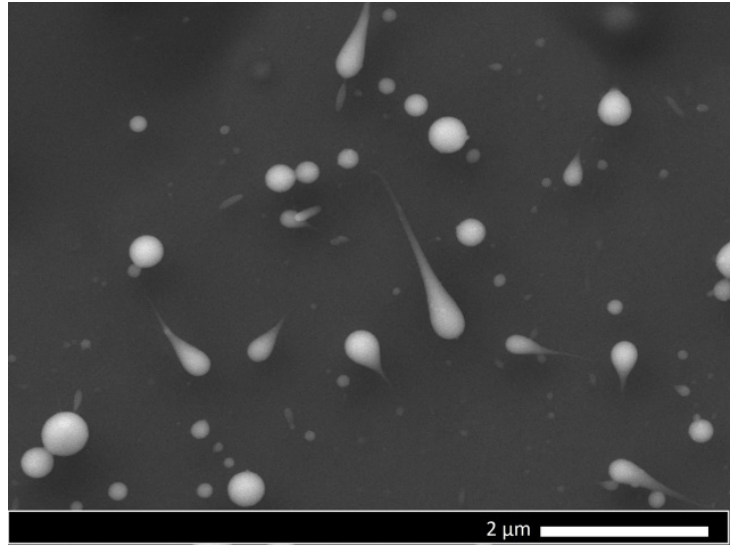

(b)

Figure 9. SEM photomicrographs of nanoparticles electrosprayed from the hyaluronic acid solutions with concentration $7.5 \mathrm{mg} / \mathrm{mL}$ under $30 \mathrm{kV}$ : (a) magnification 4000×; (b) magnification 25,000×.

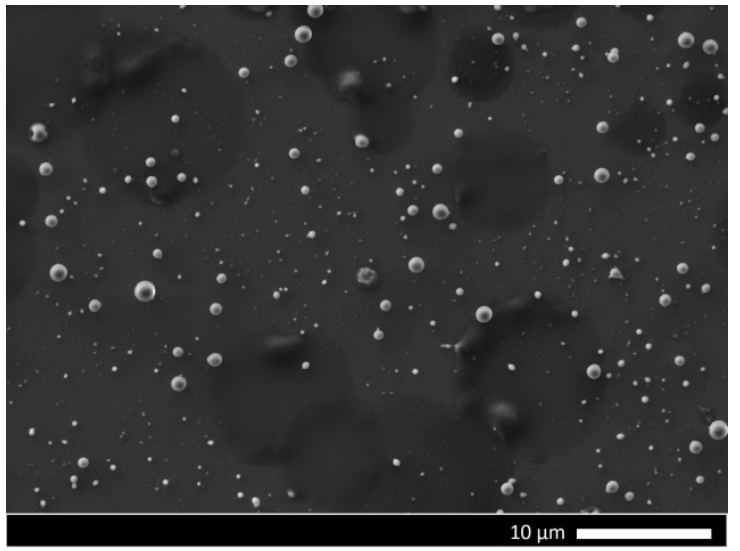

(a)

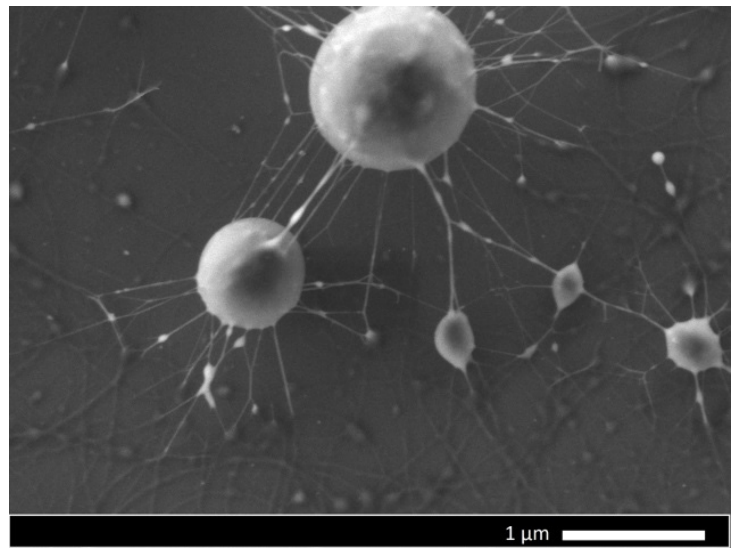

(b)

Figure 10. SEM photomicrographs of nanoparticles electrosprayed from the hyaluronic acid solutions with concentration $10.0 \mathrm{mg} / \mathrm{mL}$ under $30 \mathrm{kV}$ : (a) magnification 4000×; (b) magnification 42,000×.

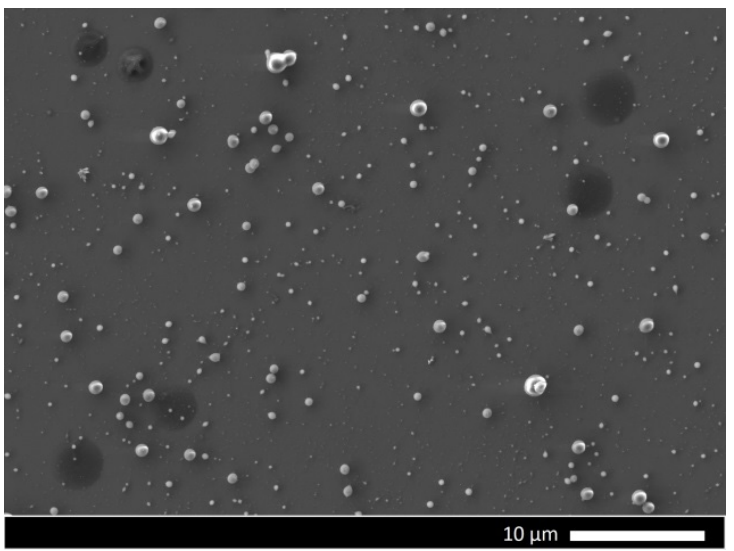

(a)

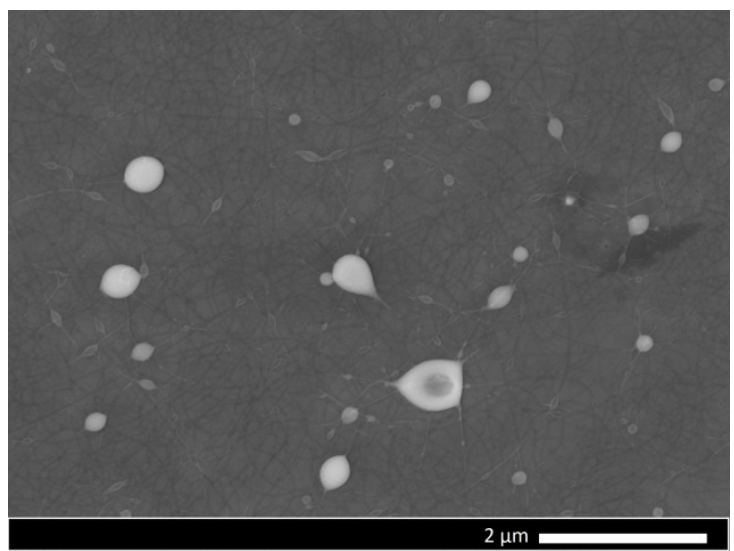

(b)

Figure 11. SEM photomicrographs of nanoparticles electrosprayed from the hyaluronic acid solutions with concentration $12.5 \mathrm{mg} / \mathrm{mL}$ under $30 \mathrm{kV}$ : (a) magnification 4000×; (b) magnification 25,000×. 


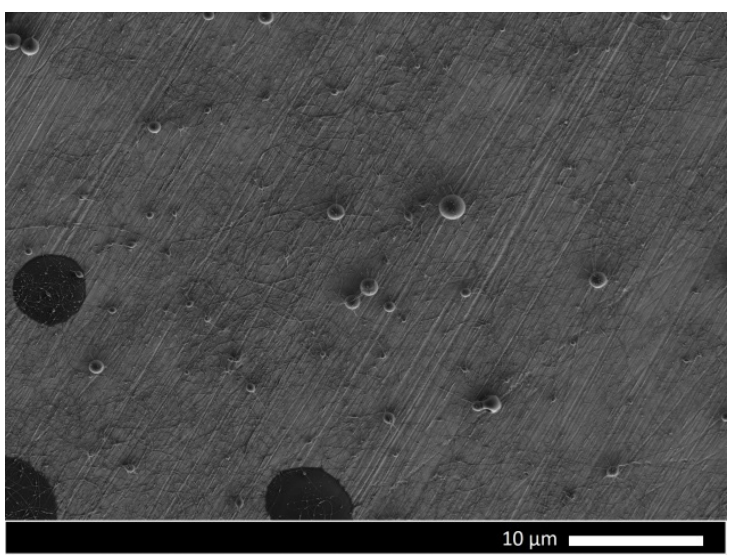

(a)

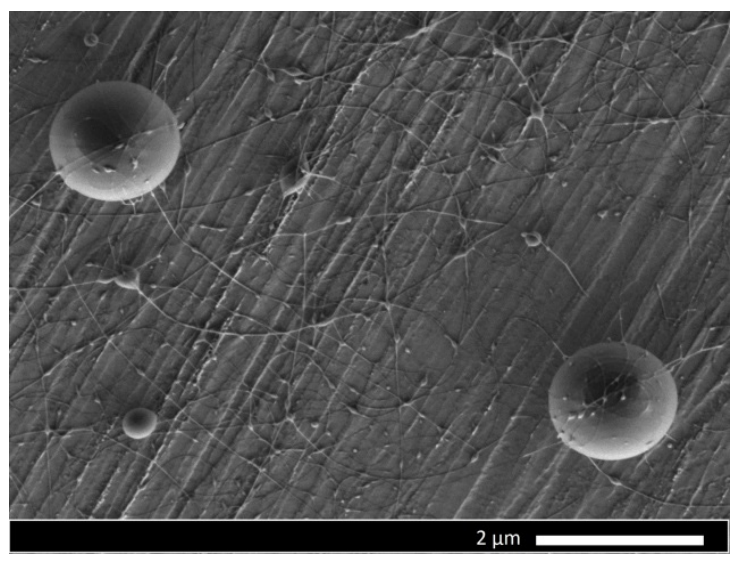

(b)

Figure 12. SEM photomicrographs of nanoparticles electrosprayed from the hyaluronic acid solutions with concentration $15.0 \mathrm{mg} / \mathrm{mL}$ under $30 \mathrm{kV}$ : (a) magnification 4000×; (b) magnification 25,000×.

Hyaluronic acid solution even at concentration $2.5 \mathrm{mg} / \mathrm{mL}$ allows to form polymer nanoparticles (see Figure 7a,b). However, in comparison with the next samples obtained from the solutions with higher concentrations, this one does not produce the samples with high coverage density. Thus, such solutions do not have a high product yield, which should be taken into consideration during further investigation.

As shown in Figures $8 \mathrm{a}, \mathrm{b}$ and $9 \mathrm{a}, \mathrm{b}$ the samples obtained have high coverage density by the polymer nanoparticles. Interestingly, some nanoparticles demonstrated in Figure $9 \mathrm{a}, \mathrm{b}$ have a comet-like form. This fact could be related to the conversion process from electrospraying to electrospinning when polymer jet from spinning needle starts to form fibers apart from particles. It is confirmed by the following microphotographs (Figure 10a,b).

When the concentration rises from $7.5 \mathrm{mg} / \mathrm{mL}$ to $10.0 \mathrm{mg} / \mathrm{mL}$, an increase in the diameter of particles and the formation of thin threads are observed which confirms the above-mentioned theory of the formation of fibers between the particles (Figure 10b). Unlike the previous nanoparticle samples with a lower concentration, nanoparticles obtained from solutions with a concentration equal to $10.0 \mathrm{mg} / \mathrm{mL}$ have a distinct sphere shape. At the same time, nanoparticles have the fibers around them looking like "spiderweb". Moreover, several nanoparticles have the form of "beads on a string", which confirms the conversion process from electrospraying to electrospinning.

With further increase in the concentration, the aggregation of the particles is observed (Figure 11a, top left). Particles revert to droplet shape and fibers become more visible.

Although the particles obtained from the solutions with the highest concentration have the largest diameter, coverage density is very low (Figure 12a). Bigger particles are surrounded by fibers with larger diameters (Figure 12b); thus, this solution would not give a high product yield.

\subsubsection{Statistical Analysis}

As shown in Figure 13a nanoparticles obtained from the solutions with a concentration equal to $2.5 \mathrm{mg} / \mathrm{mL}$ have a mean diameter of $0.297 \mu \mathrm{m}$ and diameter distribution from 0.105 to $0.897 \mu \mathrm{m}$. As the concentration rises from $2.5 \mathrm{mg} / \mathrm{mL}$ to $5.0 \mathrm{mg} / \mathrm{mL}$, a minor increase in the mean diameter of particles and a widening of diameter distribution are observed: $0.322 \mu \mathrm{m}$ and $0.116-0.938 \mu \mathrm{m}$, respectively (Figure 13b). However, with a further increase in polymer concentration to $7.5 \mathrm{mg} / \mathrm{mL}$, the mean diameter of nanoparticles decreases to $0.315 \mu \mathrm{m}$ with simultaneous narrowing of diameter distribution to a range of $0.0975-0.787 \mu \mathrm{m}$ (Figure 13c). Further raise in polymer concentration to $10.0 \mathrm{mg} / \mathrm{mL}$ results in an increase of mean particle diameter to $0.383 \mu \mathrm{m}$ with a rapid increase of diameter distribution (0.122-1.466 $\mu \mathrm{m}$, Figure 13d). As shown in Figure 13e nanoparticles obtained from the polymer solution with HA concentration $12.5 \mathrm{mg} / \mathrm{mL}$ have nearly the same mean diameter 
and diameter distribution: $0.387 \mu \mathrm{m}$ and $0.128-1.495 \mu \mathrm{m}$, respectively. A further raise in polymer concentration to $15.0 \mathrm{mg} / \mathrm{mL}$ results in rapid increase of mean particle diameter to $0.584 \mu \mathrm{m}$ with an increase of diameter distribution (0.097-1.797 $\mu \mathrm{m}$, Figure 13f).

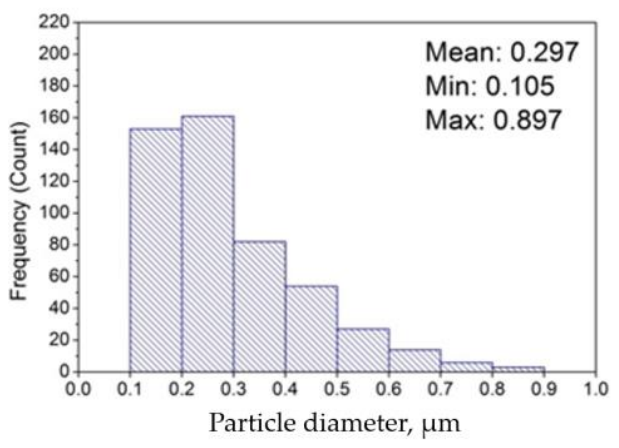

(a)

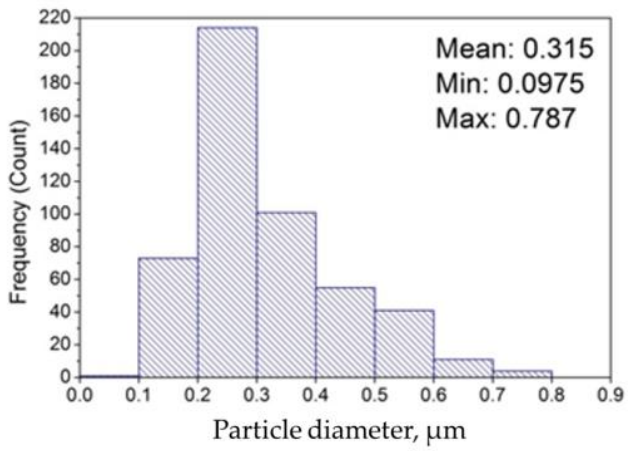

(c)

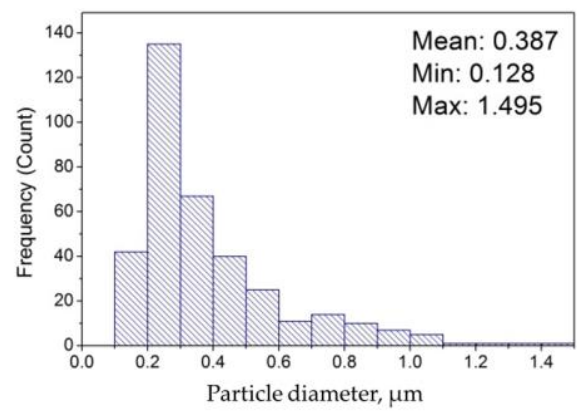

(e)

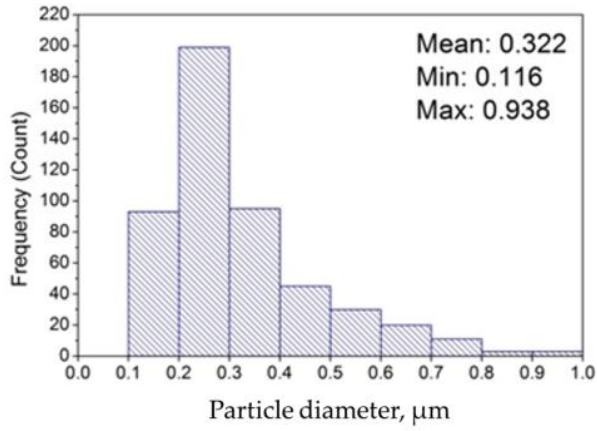

(b)

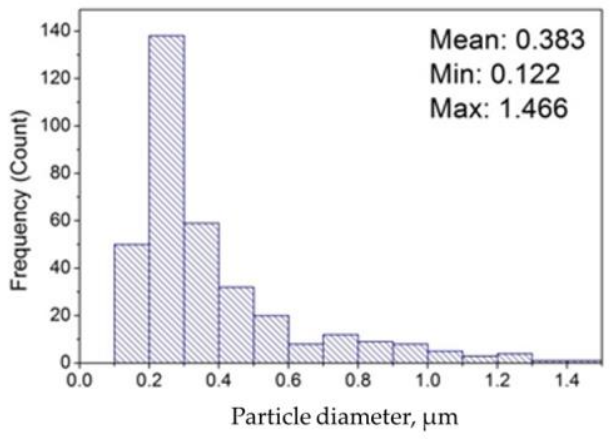

(d)

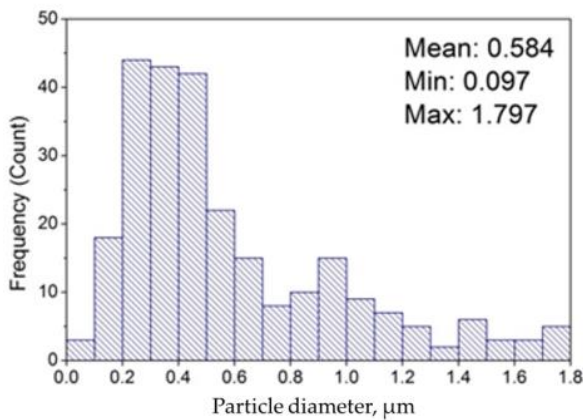

$(\mathbf{f})$

Figure 13. Diameter distribution of nanoparticles based on HA from solutions with polymer concentration equal to: (a) $2.5 \mathrm{mg} / \mathrm{mL}$; (b) $5.0 \mathrm{mg} / \mathrm{mL}$; (c) $7.5 \mathrm{mg} / \mathrm{mL}$; (d) $10.0 \mathrm{mg} / \mathrm{mL}$; (e) $12.5 \mathrm{mg} / \mathrm{mL}$; (f) $15.0 \mathrm{mg} / \mathrm{mL}$. 
The information about biopolymer nanoparticle morphology is summarized in Table 2 . The diameter distributions were obtained by ImageJ analysis of SEM photomicrographs.

Table 2. Diameter distribution of nanoparticles obtained from hyaluronic acid solutions.

\begin{tabular}{cccc}
\hline \multirow{2}{*}{ HA Concentration, $\mathbf{m g} / \mathbf{m L}$} & \multicolumn{2}{c}{ Diameter of Nanoparticles Obtained, um } \\
\cline { 2 - 4 } & Mean & Max & Min \\
\hline 2.5 & $0.297 \pm 0.145$ & 0.897 & 0.105 \\
\hline 5.0 & $0.322 \pm 0.151$ & 0.938 & 0.116 \\
\hline 7.5 & $0.315 \pm 0.125$ & 0.787 & 0.0975 \\
\hline 10.0 & $0.383 \pm 0.247$ & 1.466 & 0.122 \\
\hline 12.5 & $0.387 \pm 0.223$ & 1.495 & 0.128 \\
\hline 15.0 & $0.584 \pm 0.398$ & 1.797 & 0.097 \\
\hline
\end{tabular}

\section{Conclusions and Future Perspectives}

In this research, biopolymer nanoparticles based on native hyaluronic acid, for the first time, were successfully obtained by electrohydrodynamic jetting from distilled water solutions at ambient conditions. Nanoparticles morphology, solution electrosprayability, as well as the physical characteristics of the spraying solutions as functions of hyaluronic acid concentration, were analyzed in detail. The conclusions mentioned below could be highlighted in our study:

- Utilizing HA solutions with an optimal concentration range from 2.5 to $7.5 \mathrm{mg} / \mathrm{mL}$ provides the obtaining of polymer nanoparticles with a mean diameter equal to $300 \mathrm{~nm}$.

- Dimensions of nanoparticles combined with the negative charge of hyaluronic acid ensure the possibility of use of such nanoparticles as modern drug delivery systems, including the intravenous route of the administration.

- Physical properties of the solutions such as electrical conductivity, surface tension, and viscosity should be taken into consideration to define the optimal parameters of polymer solutions for the obtaining of nanoparticles with required structural and exploitative property packages.

- A further investigation should be aimed at in several important ways. Firstly, narrowing of diameter distributions driven by varying technological parameters results in raising the potential utilization of hyaluronic acid nanoparticles in medicine. Secondly, loading biologically active substances into the polymer nanoparticles is a challenging issue, which results in fewer side-effects of drug molecules and enhanced bioavailability and thus less dose regime. The latter opens a new direction in the field of targeted drug delivery.

Author Contributions: Conceptualization, M.U. and S.M.; formal analysis, K.Z., P.S., and R.O., investigation, P.S. and K.Z.; resources, P.S. and R.O.; writing_original draft preparation, P.S. and K.Z.; writing—review and editing, P.S., K.Z., S.M., and R.O.; visualization, P.S., K.Z., and M.B.; supervision, S.M. and M.U.; project administration, M.U.; funding acquisition, M.U. All authors have read and agreed to the published version of the manuscript.

Funding: This work was financially supported by RFBR (project number 19-33-90098).

Conflicts of Interest: The authors declare no conflict of interest.

\section{References}

1. Selyanin, M.A.; Khabarov, V.N.; Boykov, P.Y. Hyaluronic Acid: Production, Properties, Application in Biology and Medicine; John Wiley \& Sons, Ltd.: Chichester, UK, 2015; p. 215.

2. Gupta, R.C.; Lall, R.; Srivastava, A.; Sinha, A. Hyaluronic Acid: Molecular Mechanisms and Therapeutic Trajectory. Front Vet. Sci. 2019, 6, 192. [CrossRef] [PubMed]

3. Laurent, T.C.; Laurent, U.B.; Fraser, J.R. Functions of hyaluronan. Ann. Rheum. Dis. 1995, 54, 429-432. [CrossRef] [PubMed] 
4. Papakonstantinou, E.; Roth, M.; Karakiulakis, G. Hyaluronic acid: A key molecule in skin aging. Dermatoendocrinology 2012, 4, 253-258. [CrossRef] [PubMed]

5. Fallacara, A.; Baldini, E.; Manfredini, S.; Vertuani, S. Hyaluronic Acid in the Third Millennium. Polymers 2018, 10, 701. [CrossRef] [PubMed]

6. Zamboni, F.; Ryan, E.; Culebras, M.; Collins, M.N. Labile crosslinked hyaluronic acid via urethane formation using bis( $\beta$-isocyanatoethyl) disulphide with tuneable physicochemical and immunomodulatory properties. Carbohyd. Polym. 2020, 245, 116501. [CrossRef]

7. Zamboni, F.; Keays, M.; Hayes, S.; Albadarin, A.B.; Walker, G.M.; Kiely, P.A.; Collins, M.N. Enhanced cell viability in hyaluronic acid coated poly(lactic-co-glycolic acid) porous scaffolds within microfluidic channels. Int. J. Pharm. 2017, 532, 595-602. [CrossRef]

8. Brown, T. The Development of Hyaluronan as a Drug Transporter and Excipient for Chemotherapeutic Drugs. Curr. Pharm. Biotechnol. 2008, 9, 253-260. [CrossRef]

9. Ouhtit, A.; Abd Elmageed, Z.Y.; Abdraboh, M.E.; Lioe, T.F.; Raj, M.H.G. In Vivo Evidence for the Role of CD44s in Promoting Breast Cancer Metastasis to the Liver. Am. J. Pathol. 2007, 171, 2033-2039. [CrossRef]

10. Gibbs, P.; Clingan, P.R.; Ganju, V.; Strickland, A.H.; Wong, S.S.; Tebbutt, N.C.; Underhill, C.R.; Fox, R.M.; Clavant, S.P.; Leung, J.; et al. Hyaluronan-Irinotecan improves progression-free survival in 5-fluorouracil refractory patients with metastatic colorectal cancer: A randomized phase II trial. Cancer Chemother. Pharm. 2011, 67, 153-163. [CrossRef]

11. Dunuweera, S.P.; Rajapakse, R.M.S.I.; Rajapakshe, R.B.S.D.; Wijekoon, S.H.D.P.; Nirodha Thilakarathna, M.G.G.S.; Rajapakse, R.M.G. Review on Targeted Drug Delivery Carriers Used in Nanobiomedical Applications. CNANO 2019, 15, 382-397. [CrossRef]

12. Tiwari, G.; Tiwari, R.; Bannerjee, S.; Bhati, L.; Pandey, S.; Pandey, P.; Sriwastawa, B. Drug delivery systems: An updated review. Int. J. Pharm. Investig. 2012, 2, 2. [CrossRef] [PubMed]

13. Patra, J.K.; Das, G.; Fraceto, L.F.; Campos, E.V.R.; Rodriguez-Torres, M. del P.; Acosta-Torres, L.S.; Diaz-Torres, L.A.; Grillo, R.; Swamy, M.K.; Sharma, S.; et al. Nano based drug delivery systems: Recent developments and future prospects. J. Nanobiotechnol. 2018, 16, 71. [CrossRef] [PubMed]

14. Xue, J.; Wu, T.; Dai, Y.; Xia, Y. Electrospinning and Electrospun Nanofibers: Methods, Materials, and Applications. Chem. Rev. 2019, 119, 5298-5415. [CrossRef] [PubMed]

15. Mitchell, G.R. (Ed.) Electrospinning: Principles, Practice Possibilities, 1st ed.; Polymer Chemistry Series; The Royal Society of Chemistry: London, UK, 2015; ISBN 978-1-84973-556-8.

16. Agarwal, S.; Wendorff, J.H.; Greiner, A. Use of electrospinning technique for biomedical applications. Polymer 2008, 49, 5603-5621. [CrossRef]

17. Snetkov, P.; Morozkina, S.; Olekhnovich, R.; Vu, T.H.N.; Tyanutova, M.; Uspenskaya, M. Curcumin/Usnic Acid-Loaded Electrospun Nanofibers Based on Hyaluronic Acid. Materials 2020, 13, 3476. [CrossRef] [PubMed]

18. Snetkov, P.; Morozkina, S.; Uspenskaya, M.; Olekhnovich, R. Hyaluronan-Based Nanofibers: Fabrication, Characterization and Application. Polymers 2019, 11, 2036. [CrossRef]

19. Pérez, J.M.M.; Pascau, J. Image Processing with Image; Packt Publishing Ltd: Birmingham, UK, 2013.

20. Habibi, Y.; Lucia, L. Polysaccharide Building Blocks: A Sustainable Approach to the Development of Renewable Biomaterials; John Wiley \& Sons: New York, NY, USA, 2012.

21. Finkenstadt, V.L. Natural polysaccharides as electroactive polymers. Appl. Microbiol. Biotechnol. 2005, 67, 735-745. [CrossRef]

22. Haynes, W.M.; Lide, D.R.; Bruno, T.J. CRC Handbook of Chemistry and Physics, 95th ed.; CRC Press: Boca Raton, FL, USA, 2014.

23. Kargerová, A.; Pekař, M. Densitometry and ultrasound velocimetry of hyaluronan solutions in water and in sodium chloride solution. Carbohydr. Polym. 2014, 106, 453-459. [CrossRef]

24. García-Abuín, A.; Gómez-Díaz, D.; Navaza, J.M.; Regueiro, L.; Vidal-Tato, I. Viscosimetric behaviour of hyaluronic acid in different aqueous solutions. Carbohydr. Polym. 2011, 85, 500-505. [CrossRef]

25. Garg, K.; Bowlin, G.L. Electrospinning jets and nanofibrous structures. Biomicrofluidics 2011, 5, 13403. [CrossRef]

26. Ribeiro, W.; Mata, J.L.; Saramago, B. Effect of Concentration and Temperature on Surface Tension of Sodium Hyaluronate Saline Solutions. Langmuir 2007, 23, 7014-7017. [CrossRef] [PubMed] 
27. Almond, A.; Brass, A.; Sheehan, J.K. Deducing polymeric structure from aqueous molecular dynamic simulations of oligosaccharides: Prediction from simulation of hyaluronan tetrasaccharides compared with hydrodynamic and X-ray fiber diffraction date. J. Mol. Biol. 1998, 284, 1425-1437. [CrossRef] [PubMed]

28. Scott, J.E.; Heatley, F. Hyaluronan forms specific stable tertiary structures in aqueous solution: A 13C NMR stud. Natl. Acad. Sci. 1999, 96, 4850-4855. [CrossRef] [PubMed]

29. Scott, J.E.; Cummings, C.; Brass, A.; Chen, Y. Secondary and tertiary structures of hyaluronan in aqueous solution, investigated by rotary shadowing-electron microscopy and computer simulation. Hyaluronan is a very efficient network-forming polymer. Biochem. J. 1991, 274, 699-705. [CrossRef] [PubMed]

30. Atkins, E.D.; Sheehan, J.K. Hyaluronates: Relation between molecular conformations. Science 1973, 179, 562-564. [CrossRef] [PubMed]

31. Dea, I.C.; Moorhouse, M.R. Hyaluronic acid: A novel, double helical molecule. Science 1973, 179, 560-562. [CrossRef]

32. Fraser, J.R.E.; Laurent, T.C.; Laurent, U.B.G. Hyaluronan: Its nature, distribution, functions and turnover. J. Intern. Med. 1997, 242, 27-33. [CrossRef]

33. Laurent, T.C.; Laurent, U.B.; Fraser, J.R.E. The structure and function of hyaluronan: An overview. Immunol. Cell Biol. 1996, 74, a1-a7. [CrossRef]

34. Pisárčik, M.; Bakoš, D.; Čeppan, M. Non-Newtonian properties of hyaluronic acid aqueous solution. Colloids Surf. Physicochem. Eng. Asp. 1995, 97, 197-202. [CrossRef]

Publisher's Note: MDPI stays neutral with regard to jurisdictional claims in published maps and institutional affiliations.

(C) 2020 by the authors. Licensee MDPI, Basel, Switzerland. This article is an open access article distributed under the terms and conditions of the Creative Commons Attribution (CC BY) license (http://creativecommons.org/licenses/by/4.0/). 